Check for updates

Cite this: J. Mater. Chem. A, 2018, 6, 20916

Received 11th September 2018 Accepted 2nd October 2018

DOI: $10.1039 / c 8 t a 08856 j$

rsc.li/materials-a

\section{Ionic liquid containing electron-rich, porous polyphosphazene nanoreactors catalyze the transformation of $\mathrm{CO}_{2}$ to carbonates $\uparrow$}

\author{
Zhangjun Huang, ${ }^{\text {ab }}$ Jorge G. Uranga, ${ }^{a}$ Shiliu Zhou, ${ }^{\mathrm{b}}$ Haiyan Jia, ${ }^{\text {ab }}$ Zhaofu Fei, (D) *a \\ Yefeng Wang, ${ }^{a}$ Felix D. Bobbink, ID a Qinghua Lu iD *b and Paul J. Dyson (DD *a
}

\section{Introduction}

Porous polymers are formed from the reaction of rigid organic building blocks with complementary steric and geometric features. ${ }^{1}$ They have been evaluated in numerous applications including gas adsorption and storage, ${ }^{2}$ separations, ${ }^{3}$ sensors, ${ }^{4}$ opto/electronic devices, ${ }^{5}$ drug delivery and therapeutics, ${ }^{6}$ energy storage, ${ }^{7}$ and catalysis. ${ }^{8}$ However, the preparation of highly porous polymers requires reversible bond-forming conditions. ${ }^{9}$ In certain systems the pore size is adjustable and swelling of porous materials, induced by solvents, can facilitate the transport of compounds into the porous network under actual reaction conditions. ${ }^{10}$

Porous polymers have recently been evaluated in $\mathrm{CO}_{2}$ separation and conversion processes. For example, a flexible porous polymer exhibits gate opening-type abrupt adsorption for $\mathrm{C}_{2} \mathrm{H}_{2}$, but not for $\mathrm{CO}_{2}$, leading to an appreciable separation for $\mathrm{CO}_{2}$ from $\mathrm{CO}_{2} / \mathrm{C}_{2} \mathrm{H}_{2}$ mixtures at near ambient temperature $(273 \mathrm{~K}) .{ }^{11}$ A porous polymer containing an embedded ionic-polymer was used to catalyze the cycloaddition reaction of $\mathrm{CO}_{2}$ to epoxides under ambient temperature, ${ }^{12}$ although $\mathrm{Cu}(\mathrm{OAc})_{2}$ was required

Institut des Sciences et Ingénierie Chimiques, Ecole Polytechnique Fédérale de Lausanne (EPFL), CH-1015 Lausanne, Switzerland. E-mail: zhaofu.fei@epfl.ch; paul. dyson@epfl.ch

${ }^{b}$ School of Chemistry and Chemical Engineering, The State Key Laboratory of Metal Matrix Composites, Shanghai Jiao Tong University, Shanghai, P. R. China. E-mail: qhlu@sjtu.edu.cn

† Electronic supplementary information (ESI) available. See DOI: $10.1039 / \mathrm{c} 8 \mathrm{ta} 08856 \mathrm{j}$ as a co-catalyst to achieve high efficiency under ambient conditions. Cross-linked ionic polymers based on poly(styrene) and encompassing imidazolium cations catalyze this reaction in the absence of a co-catalyst and under mild conditions. ${ }^{13}$

Porous polyphosphazenes (PPZs) are prepared from the polycondensation of compounds containing o-dihydroxybenzene/ophenylenediamine groups with hexachlorocyclophosphazene (HCCP). ${ }^{\mathbf{1 4}}$ PPZs possess unique frameworks with each aromatic plane linked in a perpendicular fashion to the plane of the cyclophosphazene ring, leading to large gaps between the layers of the polymer and preventing the formation of $\pi-\pi$ stacking or Lewis acid-base interactions, which leads to flexible amorphous structures that self-assemble to form spheroids.

Herein, we describe the preparation of a new electron-rich PPZ material that forms nanospheres which exhibit solventdependent size and porosity. The PPZ nanospheres readily absorb a range of ionic liquid (IL) cations, leaving the anions largely exposed. The resulting hybrid nanospheres catalyze the reaction of $\mathrm{CO}_{2}$ and epoxides to form cyclic carbonates considerably more effectively than the pure IL. This reaction has been extensively investigated and is even conducted on an industrial scale. ${ }^{15}$

\section{Results and discussion}

The PPZ nanospheres were prepared and optimized from the polycondensation reaction between 9,10-dimethyl-9,10-ethano9,10-dihydro-2,3,6,7-tetrahydroxy-anthracene (ATC) and HCCP in the presence of triethylamine in acetonitrile (Scheme 1 and Fig. S2 $\dagger$ ). The reaction of the phenol hydroxyl group $\left(3280 \mathrm{~cm}^{-1}\right)$ 
and HCCP $\left(1209 \mathrm{~cm}^{-1}\right)$ and the formation of $\mathrm{P}-\mathrm{O}-\mathrm{Ar}$ bonds $\left(921 \mathrm{~cm}^{-1}\right)$, is apparent from the FT-IR spectrum (Fig. S3 $\dagger$ ), confirming the formation of the PPZ nanospheres. ${ }^{16}$

The ${ }^{13} \mathrm{C}$ solid state NMR spectrum of the PPZ nanospheres (Fig. 1a) shows signals centered at 9, 20, 40, 112, 140, 219 ppm, all of which are consistent with the presence of the ATC building block, providing further evidence of the incorporation of ATC into the PPZ nanospheres. The ${ }^{31} \mathrm{P}$ solid state NMR spectrum shows one broad singlet at $-1 \mathrm{ppm}$ characteristic of $\mathrm{P}(\mathrm{v})$ in a single environment (Fig. 1b). ${ }^{14 b}$

Scanning electron microscopy (SEM) and transmission electron microscopy (TEM) shows that the PPZ material comprises nanospheres (Fig. 1c and d) that are free-standing and well dispersed. Statistical analysis indicates that the PPZ nanospheres have a mean diameter of $121 \mathrm{~nm}$ and a reasonably narrow size distribution (Fig. S4 $\dagger$ ). The expected lack of longrange order is apparent from the powder X-ray diffraction (PXRD) analysis (Fig. S5 $\dagger$ ), which shows three amorphous broad peaks around 16, 39 and $41^{\circ}$. The amorphous character of PPZ material is caused by the interspersal of domains with eclipsed ordering and domains with staggered ordering, ${ }^{17}$ and the peak around $16^{\circ}$ reveals some ordering in the range 4.9 to $6.5 \AA$, presumably corresponding to shoulder-to-shoulder packing (4.9 $\AA$, staggered ordering, Fig. S6a $\dagger$ ) and head-to-head packing (6.5 $\AA$, eclipsed ordering, Fig. S6b†) of the layers. Considering the PXRD signal is relatively weak, most of the layers should pack obliquely, which leads to the macroscopic spherical shape.

The porosity of the PPZ nanospheres was established using Brunauer-Emmett-Teller (BET) surface area analysis. The $\mathrm{N}_{2}$ adsorption-desorption isotherms of the PPZ nanospheres (Fig. 1e) provide a surface area value of $128.8 \mathrm{~m}^{2} \mathrm{~g}^{-1}$ at $77 \mathrm{~K}$, with a hierarchical pore size distribution of 7,15 and $25 \AA$ for half pore widths (inset of Fig. 1e). Smaller pores, i.e. those with a half pore width $<10 \AA$, are expected to correspond to the holes created by the stacking of the frames,${ }^{18}$ and should open if the PPZ nanospheres swell. The pores with half pore widths of 15 and $25 \AA$ presumably correspond to the intrinsic size of the frameworks and the gap between the random packed frameworks, respectively. $\mathrm{CO}_{2}$ adsorption-desorption isotherms of the PPZ nanospheres conducted at $273 \mathrm{~K}$ (Fig. S7a $\dagger$ ) reveal that $\mathrm{CO}_{2}$ uptake reaches a value of $1.5 \mathrm{mmol} \mathrm{g}{ }^{-1}$ at $1 \mathrm{~atm}$. A broad adsorption/desorption hysteresis loop indicates the presence of intra-pore $\mathrm{CO}_{2}-\mathrm{PPZ}$ interactions, presumably due to polarization of $\mathrm{CO}_{2}$ by the electron-rich material leading to dipoledipole interactions that inhibits the release of $\mathrm{CO}_{2}$ at low

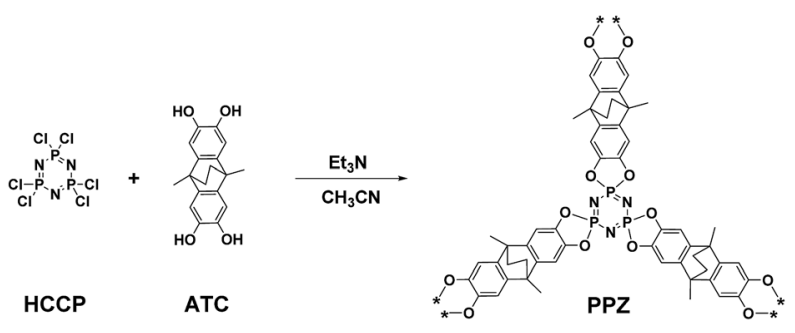

Scheme 1 Synthetic route used to prepare the PPZ material. pressures. Notably, such dipole-dipole interactions are unfavorable with $\mathrm{CH}_{4}$ which is much less polarizable (Fig. S7b †) ${ }^{19}$

The ability of the PPZ nanospheres to capture $\mathrm{CO}_{2}$, observed previously with a related material, ${ }^{14 a}$ should be advantageous in reactions employing $\mathrm{CO}_{2}$ as a substrate. Since the PPZ nanospheres are electron-rich, they can potentially interact strongly with the cations of ILs, although the dense nature of the PPZ nanospheres and relatively low porosity could reduce their accessibility. However, when the PPZ nanospheres are dispersed in solvents, the polymeric layers separate and the nanospheres swell. AFM images of the PPZ nanospheres show that the overall size of the nanospheres swells from $c a .120 \mathrm{~nm}$ (Fig. 2a and c) in dry state to $c a .236 \mathrm{~nm}$ (Fig. 2b and d) in styrene oxide (SO). Further swelling of the PPZ nanospheres is accompanied by an increase in porosity, allowing interactions with solvent molecules and solvates. Thus, the PPZ nanospheres and ILs combine in situ to afford PPZ-IL nanoreactors.

The cycloaddition of $\mathrm{CO}_{2}$ to epoxides was selected as an ideal test reaction ${ }^{20}$ as the PPZ nanospheres interact with $\mathrm{CO}_{2}$, and appear to polarize it, and therefore the absorbed $\mathrm{CO}_{2}$ could be somewhat activated. Moreover, the cycloaddition of $\mathrm{CO}_{2}$ to epoxides is of industrial importance, ${ }^{21}$ and ILs are good catalysts for this reaction, ${ }^{13 a}$ with highest activities obtained for catalysts with highly nucleophilic dynamic light scattering (DLS) shows that the extent of swelling of the PPZ nanospheres is solvent dependent (Fig. 2e). Swelling of the PPZ nanospheres in styrene oxide (SO) doubled their size, which was accompanied by an increase in porosity and catalytic activity. Due to the electron rich nature of the PPZ nanospheres, IL cations should interact strongly with them, increasing the nucleophilicity of the anions, and potentially enhancing catalytic activity. In this respect, the rate-determining step of the reaction catalyzed by imidazolium salts involves ring-opening of the epoxide by the anion. ${ }^{22}$ In this respect, the rate-determining step of the reaction catalyzed by allowing interactions with solvent molecules and solvates. Thus, the PPZ nanospheres and ILs selected as solvent and substrate for cycloaddition with $\mathrm{CO}_{2}$. Although many catalytic systems have been established for this highly atom-economic reaction,,$^{15}$ certain amorphous polymers have advantages including excellent stability, high efficiency under mild conditions, and they are readily recyclable and reusable. ${ }^{23}$ A series of ILs (Fig. 3a) with different structures were combined with the PPZ nanospheres and a schematic of a PPZ-IL interaction is shown in Fig. 3b. The PPZ nanospheres do not catalyze the cycloaddition of $\mathrm{CO}_{2}$ to SO in the absence of IL (Table 1, entry 1). In contrast, ILs that dissolve in SO under the given conditions, i.e. $57^{\circ} \mathrm{C}$ and 1 atm $\mathrm{CO}_{2}$, catalyze the reaction to afford styrene carbonate (SC) in moderate yields, with the activity being comparable to structurally related ILs. ${ }^{24}$ The PPZIL nanoreactors, which form in situ, catalyze the reaction considerably more efficiently, which is as expected due to the enhanced nucleophilicity of the IL anion. Notably, the magnitude of the enhancement in activity of the PPZ-IL nanoreactors relative to the pure IL strongly depends on the structure of the cation, with the catalytic efficiency of less sterically encumbered ILs increasing by over $100 \%$ (Table 1 , entries $2 / 3,5 / 6$ and $11 / 12$ ), and over $80 \%$ (Table 1 , entries $7 / 8,9 / 10$ and 13/14). In contrast, 

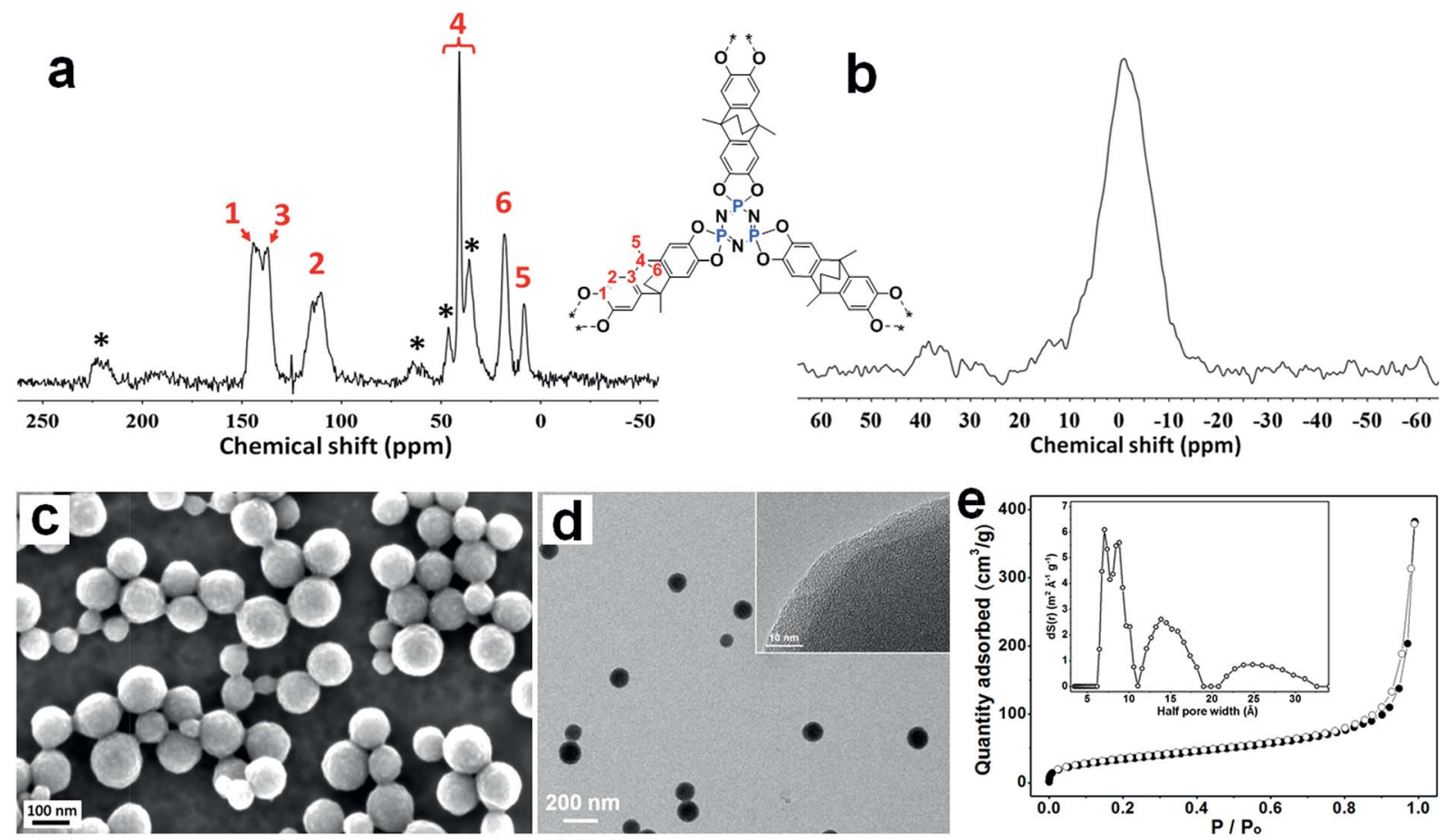

Fig. 1 (a) ${ }^{13} \mathrm{C}$ solid state NMR spectrum and (b) ${ }^{31} \mathrm{P}$ solid state NMR spectrum of the PPZ nanospheres. Side bands are indicated with stars $(*)$. (c) SEM and (d) TEM image of the PPZ nanospheres. Inset shows the high resolution image. (e) $\mathrm{N}_{2}$ adsorption-desorption isotherms of the PPZ nanospheres recorded at $77 \mathrm{~K}$. Inset shows the DFT estimated pore size distribution.
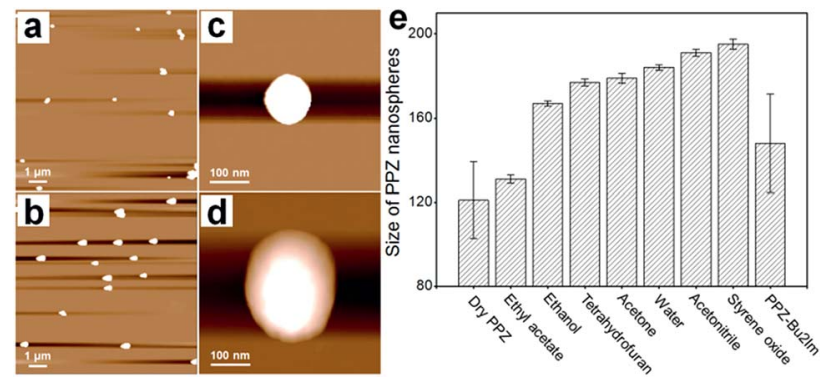

Fig. 2 AFM images of the PPZ nanospheres (a) in a dry state and (b) after swelling in SO. (c) and (d) are single particle images corresponding to (a) and (b), respectively. The size of the nanospheres was determined at $25^{\circ} \mathrm{C}$ at a concentration of $0.1 \mathrm{mg} \mathrm{mL}^{-1}$. (e) Data for the average size and standard derivation of the PPZ nanospheres when dry (determined from SEM) and when swelled in solvents (determined from DLS, Fig. S8†).

those with bulky substituents, e.g. PhIm, increase by only $c a$. $<10 \%$ (Table 1, entries 15/16) and a decrease in activity is observed for the extremely bulky cation in $4 \mathrm{PhIm}$ (Table 1 , entries 19/20). These differences in the magnitude of the reaction enhancement may be attributed to the strength of the interactions between the PPZ nanospheres and the IL, i.e. the least bulky IL cations interact strongly with the PPZ leaving the IL anion more exposed and reactive. The largest increase in activity was observed for the non-hindered bis-imidazolium salt, Bu2Im, with a $-\left(\mathrm{CH}_{2}\right)_{4}-$ linker connecting the rings, i.e. PPZ-Bu2Im led to near quantitative yields (Table 1, entry 22) whereas Bu2Im alone resulted in a yield of $14 \%$ (Table 1 , a

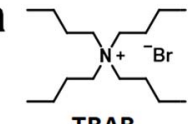

TBAB



TBAI

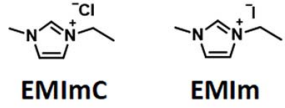

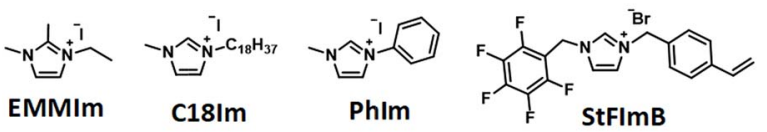

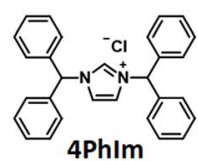

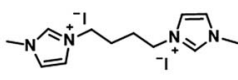

Bu2 Im

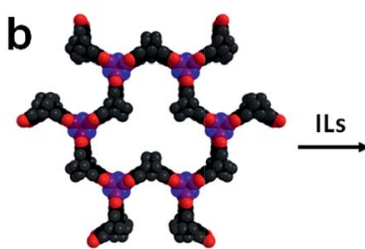

(PPZ)

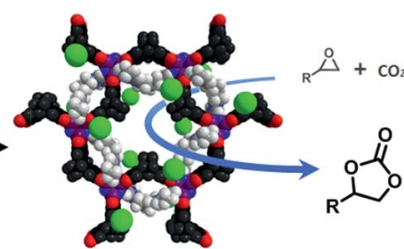

(PPZ-IL)



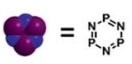

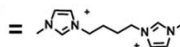

$$
\begin{aligned}
& \mathrm{C}=\mathrm{I}
\end{aligned}
$$

Fig. 3 (a) Structures of the ILs used to prepare PPZ-IL nanoreactors. (b) The proposed representation of interactions of the IL in the PPZBu2Im system.

entry 21). This represents an increase in activity of 7 -fold. It has previously been shown that hydroxyl groups can enhance the catalytic efficiency of the cycloaddition reaction of $\mathrm{CO}_{2}$ to epoxides ${ }^{25}$ however, in the PPZ nanoparticles the majority of 
Table 1 Catalytic data of cycloaddition of $\mathrm{SO}$ and $\mathrm{CO}_{2}$ catalyzed over various ILs and PPZ-IL nanoreactors ${ }^{a}$

\begin{tabular}{llclll}
\hline Entry & Catalyst & Yield (\%) & Entry & Catalyst & Yield (\%) \\
\hline 1 & PPZ & 0 & 15 & PhIm & 58 \\
2 & TBAB & 44 & 16 & PPZ-PhIm & 63 \\
3 & PPZ-TBAB $^{b}$ & 89 & 17 & StFImB & 13 \\
4 & PPZ-TBAB $^{b}$ & 89 & 18 & PPZ-StFImB & 34 \\
5 & TBAI & 37 & 19 & 4PhIm & 48 \\
6 & PPZ-TBAI & 88 & 20 & PPZ-4PhIm & 45 \\
7 & EMImC & 66 & 21 & Bu2Im & 14 \\
8 & PPZ-EMImC & 81 & 22 & PPZ-Bu2Im & 99 \\
9 & EMIm & 73 & 23 & PPZ-Bu2Im & 98 \\
10 & PPZ-EMIm & 84 & 24 & ATC + Bu2Im & 32 \\
11 & EMMIm & 41 & 25 & HCCP + Bu2Im & 14 \\
12 & PPZ-EMMIm & 89 & 26 & PPZ3-Bu2Im $^{d}$ & 63 \\
13 & C18Im & 67 & 27 & PPZ1-Bu2Im & 73 \\
14 & PPZ-C18Im & 88 & & &
\end{tabular}

${ }^{a}$ Reaction conditions: SO (480 mg, $4.00 \mathrm{mmol}$ ), $\mathrm{CO}_{2}$ (1 atm, using a balloon), $57{ }^{\circ} \mathrm{C}$ and $20 \mathrm{~h}$. ILs (2.5 mol\% halide), PPZ (19.2 mg, containing $2.5 \mathrm{~mol} \% \mathrm{~N})$. Yield determined by ${ }^{1} \mathrm{H}$ NMR spectroscopy. The selectivity of the reaction is all $>99 \%$ (determined by GC-MS). Entry 22 is shown as an example in Fig. S9 ESI. ${ }^{b}$ Using PPZ-TBAB in acetone. ${ }^{c}$ Using PPZ-Bu2Im in ethanol. ${ }^{d}$ PPZ3-Bu2Im and PPZ1Bu2Im. ${ }^{e}$ Were synthesized from with ATC : HCCP substrate ratios of $3: 1$ and $1: 1$, respectively.

hydroxyl groups in the ATC starting material are consumed, as demonstrated by the IR spectrum of the product (Fig. S3 $\dagger$ ), Moreover, the ATC starting material combined with Bu2Im is not a particularly active catalyst for the reaction (Table 1, entry 24), implying that the cation shielding effect provided by the electron-rich PPZ material is responsible for the enhancements in catalytic activity. While the ATC : HCCP substrate ratios of PPZ was $3: 1$ (PPZ3) and $1: 1$ (PPZ1), the conversion efficiency of corresponding nanoreactors decreased (entries 26/27), due to the interfere of defects to the interaction between Bu2Im and PPZ.

In order to better understand the differences in catalytic activity, DFT calculations were performed on three ILs as representative examples, including the systems with the best and worst enhancements in activity when combined in PPZ-IL nanoreactors, i.e. PPZ-Bu2Im, PPZ-EMIm and PPZ-4PhIm.

First, the three ILs, Bu2Im, EMIm and 4PhIm, were independently optimized, and the most stable conformation showed hydrogen bonds (HBs) as the main interaction. Only in the case of EMIm the conformation with "on top" electrostatic $\mathrm{I}^{-}$-imidazolium ${ }^{+}$interaction was also important, but for comparative purpose our analysis only considered the $\mathrm{HB}$ conformation. For Bu2Im and EMIm, the iodide interacts with the $\mathrm{C}_{2}-\mathrm{H}$ bond from the imidazolium ring, whereas, $4 \mathrm{PhIm}$ exhibits a HB network between the chloride anion and the four aromatic $\mathrm{C}-\mathrm{H}$ bonds at the ortho position with an average $\mathrm{HB}$ distance of $2.44 \AA$ A. Optimized geometries of the ILs are presented in Fig. 4a, with HBs shown in yellow and the optimized structures of the adducts, i.e. PPZ-Bu2Im, PPZ-EMIm and PPZ-
4PhIm are illustrated in Fig. 4c, with HBs shown in green and yellow. The PPZ moiety is represented by means of electrostatic potential map (see Fig. 4b) and, as expected, the phosphazene and dihydroxyphenyl rings are more electron rich than other regions. Hence, the phosphazene ring interacts preferentially with the IL cations.

Once the PPZ-Bu2Im adduct is formed, the stronger HB interactions are between the imidazolium cation and the phosphazene ring. Moreover, the orientation of imidazolium ring is not parallel to any of the $\pi$ systems in the PPZ structure, i.e. $\pi-\pi$ stacking interactions are not observed (see adducts $\mathrm{A}$ and B, Fig. 4c). Instead, HBs (marked in green in Fig. 4c) appear to be responsible of adduct formation. In contrast, the smaller IL (EMIm) interacts forms $\pi-\pi$ stacking interactions between the imidazolium and $\mathrm{PZ}$ ring (see adduct $\mathrm{D}$ ) or phenyl ring in the polymer (see adduct $\mathrm{E}$ ) with an average distance between the rings of $3.50 \AA$ for adduct D, and $3.55 \AA$ for adduct E. In the case of the more sterically hindered $4 \mathrm{PhIm}$ system, the main interactions between PPZ and IL cation comprise HBs with the aromatic and benzylic $\mathrm{C}-\mathrm{H}$ bonds (see green lines in adduct $\mathrm{C}$ ). This leads to a more compact adduct in which the $4 \mathrm{PhIm}$ occupies most of the free space inside the PPZ framework. Note that due to the high volume of 4 PhIm only one stable conformation was found.

A binding energy (BE) of $34.7 \mathrm{kcal} \mathrm{mol}^{-1}$ was calculated for the most stable conformer of PPZ-Bu2Im in the gas phase (adduct $\mathrm{A}$ in Table 2). Adduct $\mathrm{B}$, is slightly less stable than adduct $\mathrm{A}$ (binding energy $=33.7 \mathrm{kcal} \mathrm{mol}^{-1}$ ). Lower binding energies were computed for PPZ-EMIm, with values of $21.1 \mathrm{kcal} \mathrm{mol}^{-1}$ for adduct D and $25.1 \mathrm{kcal} \mathrm{mol}^{-1}$ for adduct E. Intermediate stability is predicted for PPZ-4PhIm.

HBs in ILs are evidenced by changes in the $\mathrm{C}_{\mathrm{sp}^{2}}-\mathrm{H}$ stretching frequencies in their IR spectra. ${ }^{26}$ Notably, the $\mathrm{C}_{\mathrm{sp}^{2}}-\mathrm{H}$ stretching frequency moves to lower energy as the strength of the $\mathrm{HB}$ increases and the distance between the $\mathrm{CH}$ group and the halide shortens. ${ }^{27}$ Taking these properties into account, our analysis was carried out considering the geometric and vibrational changes on the IL structure before and after adduct formation, as a descriptor of HB strength between the IL fragments. The frequency shift was calculated according to the formula $\Delta \nu=\nu \mathrm{CH}_{\mathrm{PPZ}-\mathrm{IL}}-\nu \mathrm{CH}_{\mathrm{IL}}$, where $\nu \mathrm{CH}_{\mathrm{PPZ}-\mathrm{IL}}$ represents the stretching frequency of the $\mathrm{C}_{\mathrm{sp}^{2}}-\mathrm{H}$ bonds in the adduct, and $\nu \mathrm{CH}_{\mathrm{IL}}$ the corresponding stretching frequency in the isolated ionic liquid. Accordingly, the analyzed frequency shifts were derived from the calculated $\nu \mathrm{CH}_{\mathrm{IL}}$ for the isolated ILs as reference (see Table 2), i.e. $3036 \mathrm{~cm}^{-1}$ for Bu2Im, $2987 \mathrm{~cm}^{-1}$ for EMIm, and 3166 and $3173 \mathrm{~cm}^{-1}$ for the asymmetric and symmetric stretching modes in $4 \mathrm{PhIm}$. In addition, the changes in $\mathrm{CH} \cdots \mathrm{X}$ distances were estimated from the initial values of isolated ILs, i.e. 2.51 $\AA$ for PPZ-Bu2Im, $2.46 \AA$ for PPZ-EMIm and $2.44 \AA$ for $4 \mathrm{PhIm}$ (see Table 2).

In the case of adduct $\mathrm{A}$, which involves a double imidazolium iodide structure, there are two different $\mathrm{C}(2)-\mathrm{H} \cdots \mathrm{I}_{1}$ and $\mathrm{C}(2)-$ $\mathrm{H} \cdots \mathrm{I}_{2}$ moieties in which a reduction of the $\mathrm{C}-\mathrm{H}$ stretching frequencies from the initial value was calculated, $186 \mathrm{~cm}^{-1}$ for $\mathrm{C}(2)-\mathrm{H} \cdots \mathrm{I}_{1}$ and $213 \mathrm{~cm}^{-1}$ for $\mathrm{C}(2)-\mathrm{H}^{\cdots} \mathrm{I}_{2}$ (Table 2, adduct $\mathrm{A}$ ). In parallel the $\mathrm{C}(2)-\mathrm{H} \cdots \mathrm{I}_{1} \mathrm{HB}$ is elongated by $0.22 \AA$ and the $\mathrm{C}(2)-$ 




Fig. 4 (a) Optimized geometries for ILs Bu2Im, EMIm and 4Phlm. H-bonding interactions shown as yellow with their corresponding distances. (b) Schematic representation of the optimized PPZ (represented as an electrostatic potential map according to the adjacent scale), and (c) PPZ-IL adducts for: PPZ-Bu2Im (adducts A and B), PPZ-4PhIm (adduct C) and PPZ-EMIm (adducts D and E). In addition, the main H-bonds and their corresponding distances are indicated using green lines for PPZ-cation interactions and using yellow lines for cation-anion interactions. The main $\mathrm{H}$-bonds were identified by changes in $\mathrm{C}-\mathrm{H}$ vibrations and only the $\mathrm{H}$-bonds with distances $<3 \AA$ are shown. Two constraints (fixed distances) were included in the optimization of the PPZ structure (shown as purple lines).

$\mathrm{H}^{\cdots} \mathrm{I}_{2} \mathrm{HB}$ is elongated by $0.20 \AA$ relative to the initial value of $2.51 \AA$ (Table 2, Bu2Im). In adduct B, frequency shifts relative to those in the isolated IL of $159 \mathrm{~cm}^{-1}$ and $177 \mathrm{~cm}^{-1}$ for $\mathrm{C}(2)-\mathrm{H} \cdots$ $\mathrm{I}_{1}$ and $\mathrm{C}(2)-\mathrm{H}^{\cdots} \mathrm{I}_{2}$ are calculated, respectively, with corresponding $\mathrm{H} \cdots \mathrm{I}$ elongations of 0.13 and $0.18 \AA$. In the case of adduct $\mathrm{D}$, frequency shift of $163 \mathrm{~cm}^{-1}$ and $\mathrm{H} \cdots \mathrm{I}$ distance increase of $0.12 \AA$ were obtained for the corresponding $\mathrm{C}(2)-$ $\mathrm{H} \cdots^{-I}$ moiety. Similarly with adduct $\mathrm{E} \Delta \nu$ and $\Delta r$ were $123 \mathrm{~cm}^{-1}$ and 0.10 A respectively, upon adduct formation. These changes indicate that formation of the PPZ-EMIm adduct has a weaker effect on the ion-pair association compared to the PPZ-Bu2Im system (adducts A and B). Thus, HB strength calculations may be used to rationalize the changes in reactivity of systems before and after adduct formation with the PPZ material, in that the anion interacts less strongly with the cation in the PPZ-Bu2Im than in the PPZ-EMIm systems, and is therefore more nucleophilic and hence more reactive.

For PPZ-4PhIm, no important geometric and vibrational changes in IL structure were observed before and after adduct formation. For example, the average $\mathrm{C}-\mathrm{H} \cdots \mathrm{Cl}$ distances $(\mathrm{H}-$ bonding network) in the adduct PPZ-4PhIm are comparable with those observed in isolated $4 \mathrm{PhIm}$. The same was calculated

Table 2 Geometric and vibrational parameters before and after PPZ-IL adduct formation

\begin{tabular}{|c|c|c|c|}
\hline Structure & Binding energy ${ }^{a}$ & $r \mathrm{C}_{\mathrm{sp}^{2} \mathrm{H}} \cdots \mathrm{X}^{b} / \Delta r r \mathrm{C}_{\mathrm{sp}^{2} \mathrm{H}} \cdots \mathrm{X}^{c}$ & $\nu \mathrm{C}_{\mathrm{sp}^{2}}-\mathrm{H}^{e} / \Delta \nu \mathrm{C}_{\mathrm{sp}^{2}}-\mathrm{H}^{f}$ \\
\hline Isolated Bu2Im & & $\left(\mathrm{I}_{1}=\mathrm{I}_{2}\right) 2.51$ & 3036 \\
\hline PPZ-Bu2Im (A) & 34.7 & $\left(\mathrm{I}_{1}\right) 2.73 ;\left(\mathrm{I}_{2}\right) 2.71, \Delta r_{1}=0.22 ; \Delta r_{2}=0.20$ & $\left(\nu_{1}\right) 3222 ;\left(\nu_{2}\right) 3249, \Delta \nu_{1}=186 ; \Delta \nu_{2}=213$ \\
\hline $\begin{array}{l}\text { lsolated 4PhIm } \\
\text { PPZ-4PhIm (C) }\end{array}$ & 25.8 & $\begin{array}{l}2.44^{a} \\
2.46^{d}, \Delta r=0.02\end{array}$ & $\begin{array}{l}3164^{g}, 3173^{h} \\
3163^{g}, 3169^{h}, \Delta \nu^{g}=-1 ; \Delta \nu^{h}=-4\end{array}$ \\
\hline Isolated EMIm & & 2.46 & 2987 \\
\hline
\end{tabular}

${ }^{a}$ Calculated binding energies in kcal mol ${ }^{-1} .{ }^{b} \mathrm{H} \cdots \mathrm{Y}$ distances in $\AA .{ }^{c}$ Computed changes in $\mathrm{CH} \cdots \mathrm{X}$ distance in $\AA .{ }^{d}$ Average $\left(\mathrm{C}_{\text {ortho }}\right) \mathrm{H} \cdots \mathrm{X}$ distance in A. ${ }^{e}$ Calculated $\mathrm{C}_{2}-\mathrm{H}$ or $\mathrm{C}_{\text {ortho }}-\mathrm{H}$ stretching frequencies in $\mathrm{cm}^{-1} .{ }^{f}$ Computed changes in above mentioned frequencies. ${ }^{g}$ Asymmetric $\mathrm{C}_{\text {ortho }}-\mathrm{H}$ stretching. ${ }^{h}$ Symmetric $\mathrm{C}_{\text {ortho }}-\mathrm{H}$ stretching. $\left(\nu_{1}\right)$ vibrational mode for the imidazolium ring 1 and $\left(\nu_{2}\right)$ vibrational mode for ring 2. 

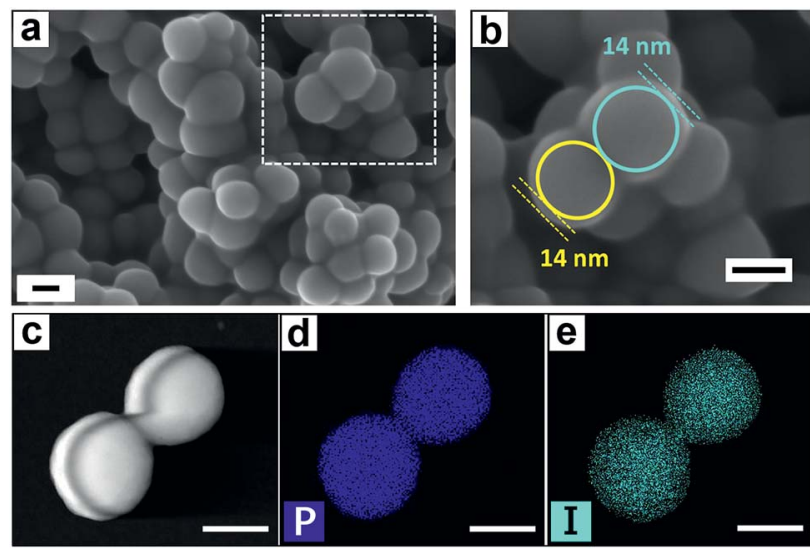

Fig. 5 (a) SEM image of the recovered PPZ-Bu2Im nanoreactors with an average size of $174 \mathrm{~nm}$. (b) Circular fitting on the enlarged area shows that the thickness of Bu2 $1 \mathrm{~m}$ is $14 \mathrm{~nm}$. (c) Scanning TEM (STEM) image, (d) P and (e) I of EDS elemental mapping of the PPZ-Bu2Im nanoreactors after washing. The scale bar is $100 \mathrm{~nm}$.

Table 3 Cycloaddition reaction of $\mathrm{CO}_{2}$ to a series of epoxides catalyzed by PPZ-Bu2Im

\begin{tabular}{|c|c|c|c|c|}
\hline Entry & Epoxide & Product & Time (h) & Yield (\%) \\
\hline $1^{a}$ & & & 3 & 99 \\
\hline 2 & & & 3 & 99 \\
\hline 3 & & & 4 & 99 \\
\hline 4 & & & 20 & 99 \\
\hline 5 & & & 4 & 99 \\
\hline
\end{tabular}

${ }^{a}$ Reaction conditions: epoxide $(4.00 \mathrm{mmol}), \mathrm{CO}_{2}$ (entry 1,10 bar $\mathrm{CO}_{2}$ in an autoclave; others, $1 \mathrm{~atm}$ using a $\mathrm{CO}_{2}$-filled balloon), $57{ }^{\circ} \mathrm{C}$. Bu2 Im (23.7 mg, $1.25 \mathrm{~mol} \%$ ), PPZ (19.2 mg, containing $2.5 \mathrm{~mol} \% \mathrm{~N}$ ). Yield was determined by ${ }^{1} \mathrm{H}$ NMR spectroscopy. The selectivity of the products is all above $99 \%$ by GC-MS.

for the $\mathrm{C}_{\text {ortho }}-\mathrm{H}$ bonds for which stretching frequency were reduced by only 1 and $4 \mathrm{~cm}^{-1}$. This suggests that the interaction between IL ion pairs is still significant and the chloride anion is less nucleophilic. Indeed, the chloride anion shown to be encapsulated within the HB network of the cation and in part by the surrounding PPZ material. As a result, it is less accessible and thus less reactive.

According to the computational results, the structure of the cation in ILs is strongly influenced by the interaction with the PPZ support and, consequently, determines the degree of activation of the anion which could be estimated from the strength of the H-bonds.
The kinetic profiles for the PPZ-Bu2Im nanoreactors and the Bu2Im IL are compared in Fig. S10, $\uparrow$ showing that the former is considerably more active. These differences between the PPZBu2Im nanoreactors and the other PPZ-IL nanoreactors may be attributed to the superior interaction of the Bu2Im cation with the PPZ nanospheres (see computational results above and Fig. 4c). The PPZ-IL nanoreactors form in various solvents such as acetone or ethanol and exhibit similar catalytic activities to those formed in situ in SO (Table 1, cf. entries 4 and 23 with entries 3 and 22). The PPZ-Bu2Im nanoreactors were recycled and reused 5 times with the yield of SC remaining above 95\% (Fig. S11†). The slight decrease in activity may be attributed to ca. $2 \%$ loss of the Bu2Im IL after each reaction. No changes to the catalyst were detected by solid-state ${ }^{31} \mathrm{P}$ NMR spectroscopy (Fig. S12 $\dagger$ ). The SEM image of the PPZ-Bu2Im nanoreactors after catalysis (Fig. 5a) shows them to be coated by a smooth $14 \mathrm{~nm}$ thick layer (Fig. 5b), corresponding to the precipitated Bu2Im IL in ethyl acetate (poor solvent). After removing the excess Bu2Im coating by washing with anhydrous ethanol and ethyl acetate, the PPZ nanomaterial presented a bigger diameter of $c a .150 \mathrm{~nm}$ (Fig. 5c) than the that of the freshly prepared PPZ (ca. $121 \mathrm{~nm}$ ), due to the residual Bu2Im inside (elemental mapping of EDS), Fig. $5 \mathrm{~d}$, e and $\mathrm{S} 13, \dagger$ which has a detection depth of c.a. $100 \mathrm{~nm} .^{28}$ The amount of the residual IL was estimated to be $24 \%$ from thermogravimetric analysis (Fig. S14 $\dagger$ ).

The scope of the PPZ-Bu2Im nanoreactors in the cycloaddition of $\mathrm{CO}_{2}$ to various epoxides was studied at atmospheric pressure (Table 3), with the corresponding carbonates obtained in excellent yields.

\section{Conclusions}

Electron-rich, semi-porous and swellable PPZ nanospheres were prepared using a facile polycondensation reaction. The PPZ nanospheres are thermally stable and can absorb $\mathrm{CO}_{2}$ under ambient conditions with weak interactions formed with the framework. The PPZ material interacts with IL cations, in particular the bis-imidazolium Bu2Im cation, to form PPZ-IL nanoreactors, which catalyze the cycloaddition of $\mathrm{CO}_{2}$ to epoxides to form cyclic carbonates under mild reaction conditions. Highest activities are obtained when the IL fits intimately into the PPZ host material, as demonstrated by DFT calculations, which reduces interactions between the cation and anion of the IL, leading to more nucleophilic anions and higher activities with catalytic efficiency exceeding 7-fold. Importantly, the PPZBu2Im nanoreactors are stable, tolerant to a range of substrates, and can be recycled and reused multiple times. Such activity is essential for this industrially important reaction and it is likely that this new class of nanoreactor can be adapted to many other transformations.

\section{Experimental}

\section{Materials and methods}

All starting materials and solvents were obtained from commercial sources and used as received. The following compounds were prepared using literature procedures: 3-ethyl- 
1,2-dimethylimidazolium iodide (EtMMIm), 3,3'-(butane-1,4diyl)bis(1-methylimidazolium)iodide (Bu2Im), 3-methyl-1octadecylimidazolium iodide (C18Im), 1,3-dibenzhydrylimidazolium chloride (4PhIm), 3-methyl-1-phenylimidazolium iodide (PhMIm), 1-((perfluorophenyl)methyl)-3-(4-vinylbenzyl)-1 $H$ imidazol-3-ium bromide (StFImB), and 9,10-dimethyl-9,10-ethano9,10-dihydro-2,3,6,7-tetrahydroxy-anthracene (ATC). ${ }^{29}$

\section{Synthesis of EtMMIm}

Iodoethane $(15.60 \mathrm{~g}, 100 \mathrm{mmol})$ was slowly added to a dry THF solution $(200 \mathrm{~mL})$ of 1,2-dimethylimidazole $(9.61 \mathrm{~g}, 100 \mathrm{mmol})$. The mixture was stirred at reflux under a nitrogen atmosphere for $2 \mathrm{~d}$. The solid obtained was removed by filtration and washed with dry ethyl ether, dissolved in methanol, and recrystallized by addition of dry ethyl ether at $-20^{\circ} \mathrm{C}$. The white solid was obtained by filtration and dried under vacuum. Yield: 81\%. FT-IR (neat): 3121, 3094, 2970, 1739, 1639, 1579, 1534, 1452, 1415, 1347, 1283, 1228, 1201, 1132, 1091, 1041, 855, 808, $772,726,667,630 \mathrm{~cm}^{-1} .{ }^{1} \mathrm{H}$ NMR $\left(400 \mathrm{MHz}\right.$, DMSO- $\left.d_{6}\right) \delta 7.67(\mathrm{~s}$, $2 \mathrm{H}), 4.15(\mathrm{~s}, 2 \mathrm{H}), 3.75(\mathrm{~s}, 3 \mathrm{H}), 2.59(\mathrm{~s}, 3 \mathrm{H}), 1.33(\mathrm{~s}, 3 \mathrm{H}) .{ }^{13} \mathrm{C} \mathrm{NMR}$ $\left(101 \mathrm{MHz}\right.$, DMSO- $\left.d_{6}\right) \delta 144.51,122.82,120.77,43.25,35.16$, 15.34, 9.63. HR-ESI-MS: $125.1073\left(\mathrm{C}_{7} \mathrm{H}_{13} \mathrm{~N}_{2}^{+}\right.$; calc. 125.1083). Anal. calcd. For $\mathrm{C}_{7} \mathrm{H}_{13} \mathrm{~N}_{2} \mathrm{I}$ : C, 33.35; H, 5.20; N, 11.11; I, 50.34. Found: C, 33.51; H, 5.60; N, 11.40; I, 50.14.

\section{Synthesis of Bu2Im}

1,4-Diiodobutane $(30.99 \mathrm{~g}, 100 \mathrm{mmol})$ was gradually added to an acetonitrile solution $(60 \mathrm{~mL})$ of 1-methylimidazole $(16.42 \mathrm{~g}$, $200 \mathrm{mmol}$ ). The mixture was stirred at reflux under a nitrogen atmosphere for $3 \mathrm{~d}$. The solution was then condensed by evaporation, and was washed by diethyl ether. The salt was precipitated as a brown powder, which was recrystallized from ethanol/diethyl ether for several times, and dried under vacuum. The purified product was finally obtained as a white solid. Yield: 76\%. FT-IR (neat): 3132, 3072, 2979, 2939, 2911, 1628, 1556, 1451, 1436, 1339, 1311, 1230, 1158, 1106, 816, 780, 756, 696, 636, 615, $595 \mathrm{~cm}^{-1} .{ }^{1} \mathrm{H}$ NMR $\left(400 \mathrm{MHz}\right.$, DMSO- $\left.d_{6}\right)$ $\delta 9.12(\mathrm{~s}, 2 \mathrm{H}), 7.75(\mathrm{~m}, 4 \mathrm{H}), 4.21(\mathrm{~s}, 4 \mathrm{H}), 3.86(\mathrm{~s}, 6 \mathrm{H}), 1.78(\mathrm{~s}, 4 \mathrm{H})$. ${ }^{13} \mathrm{C}$ NMR $\left(101 \mathrm{MHz}\right.$, DMSO- $\left.d_{6}\right) \delta 137.04,124.16,122.70,48.48$, 36.36, 26.56.

\section{Synthesis of C18Im}

1-Iodooctadecane $(38.04 \mathrm{~g}, 100 \mathrm{mmol})$ was added to an acetonitrile solution $(50 \mathrm{~mL})$ of 1-methylimidazole $(8.21 \mathrm{~g}, 100$ $\mathrm{mmol})$. The solution was stirred under reflux for $2 \mathrm{~d}$, and the resulting yellow solution was concentrated and precipitated in diethyl ether. The solid precipitation was collected by filtration, and dried under vacuum. Yield: 79\%. FT-IR (neat): 3092, 2915, 2848, 1564, 1468, 1377, 1166, 1080, 1020, 826, 735, 721, 645, $617 \mathrm{~cm}^{-1} \cdot{ }^{1} \mathrm{H}$ NMR $\left(400 \mathrm{MHz}\right.$, DMSO- $\left.d_{6}\right) \delta 9.10(\mathrm{~d}, J=1.7 \mathrm{~Hz}$, $1 \mathrm{H}), 7.73(\mathrm{dt}, J=26.7,1.8 \mathrm{~Hz}, 2 \mathrm{H}), 4.14(\mathrm{t}, J=7.2 \mathrm{~Hz}, 2 \mathrm{H}), 3.84$ (s, 3H), 1.77 (p, $J=7.4 \mathrm{~Hz}, 2 \mathrm{H}), 1.23(\mathrm{~s}, 30 \mathrm{H}), 0.95-0.77$ (m, 3H). ${ }^{13} \mathrm{C}$ NMR $\left(101 \mathrm{MHz}\right.$, DMSO- $\left.d_{6}\right) \delta 136.94,124.07,122.73,49.23$, $36.24,31.76,29.85,29.50,29.46,29.42,29.29,29.17,28.85$, 25.96, 22.56, 14.42. Anal. calc. for $\mathrm{C}_{22} \mathrm{H}_{43} \mathrm{IN}_{2}$ (462.50): C $57.13, \mathrm{H}$ 9.37, N 6.06; found C 56.98, H 9.32, N 5.89.

\section{Synthesis of 4PhIm}

A mixture of (trimethylsilyl)imidazole (14.026 g, $0.100 \mathrm{~mol})$ and chlorodiphenylmethane $(40.5 \mathrm{~g}, 0.2 \mathrm{~mol})$ in acetonitrile $(200$ $\mathrm{mL}$ ) was refluxed for $24 \mathrm{~h}$. After removal of the solvents, the resulting solid was filtered, washed with diethyl ether $(3 \times 30$ $\mathrm{mL}$ ), and dried under vacuum for $24 \mathrm{~h}$. Yield: $98 \%$. FT-IR (neat): 3166, 3069, 2977, 1536, 1492, 1452, 1183, 1138, 1078, 1030, 854, 838, 749, 737, 693, 661, 637, 592, $508 \mathrm{~cm}^{-1} .{ }^{1} \mathrm{H}$ NMR $(400 \mathrm{MHz}$, DMSO- $\left.d_{6}\right) \delta 9.34(\mathrm{t}, J=1.7 \mathrm{~Hz}, 1 \mathrm{H}), 7.83(\mathrm{~d}, J=1.7 \mathrm{~Hz}, 2 \mathrm{H}), 7.58-$ $7.24(\mathrm{~m}, 20 \mathrm{H}), 7.20(\mathrm{~s}, 2 \mathrm{H}), 3.32(\mathrm{~s}, 2 \mathrm{H}) .{ }^{13} \mathrm{C}$ NMR $(101 \mathrm{MHz}$, DMSO- $\left.d_{6}\right) \delta 137.52,129.63,129.43,128.59,123.34,66.50$.

\section{Synthesis of PhMIm}

A mixture of methyl iodide $(17.03 \mathrm{~g}, 120 \mathrm{mmol})$ and phenylimidazole $(14.41 \mathrm{~g}, 100 \mathrm{mmol})$ in acetonitrile $(200 \mathrm{~mL})$ was refluxed for $48 \mathrm{~h}$ under $\mathrm{N}_{2}$. The solvent was removed under reduced pressure, the crude product was recrystallized from acetone and ether, and the product was obtained as white solid. Yield: $80 \%$. FT-IR (neat): 3171, 3120, 1584, 1557, 1451, 1428, 1189, 1156, 1110, 1028, 821, 733, 651, 618, $554 \mathrm{~cm}^{-1} .{ }^{1} \mathrm{H}$ NMR $\left(400 \mathrm{MHz}\right.$, DMSO- $\left.d_{6}\right) \delta 9.80(\mathrm{~d}, J=1.7 \mathrm{~Hz}, 1 \mathrm{H}), 8.31(\mathrm{t}, J=1.9 \mathrm{~Hz}$, $1 \mathrm{H}), 7.99(\mathrm{t}, J=1.8 \mathrm{~Hz}, 1 \mathrm{H}), 7.86-7.51(\mathrm{~m}, 5 \mathrm{H}), 3.97(\mathrm{~s}, 3 \mathrm{H}) .{ }^{13} \mathrm{C}$ NMR (101 MHz, DMSO- $\left.d_{6}\right) \delta 136.44,135.20,130.69,130.22$, 124.92, 122.30, 121.42, 36.74 .

\section{Synthesis of StFImB}

4-Vinylbenzylimidazole $(1.0 \mathrm{~g}, 5.43 \mathrm{mmol})$ was gradually added to an acetonitrile solution $(5 \mathrm{~mL})$ of bromopentafluorobenzene $(1.20 \mathrm{~g}, 4.86 \mathrm{mmol})$. The mixture was stirred and heated to $60^{\circ} \mathrm{C}$ under a nitrogen atmosphere for $2 \mathrm{~h}$. The solution was then condensed by evaporation, and was washed by ethyl acetate. The salt was precipitated as a white powder, which was sonicated for $1 \mathrm{~h}$ and collected by filtration, washed with diethyl ether and dried. Yield: $95 \% .{ }^{1} \mathrm{H}-\mathrm{NMR}\left(400 \mathrm{MHz}\right.$, DMSO- $\left.d_{6}\right)$ : 9.52 $(\mathrm{s}, 1 \mathrm{H}) ; 7.93(\mathrm{~d}, J=14.8,2 \mathrm{H}) ; 7.61(\mathrm{~d}, J=8.2,2 \mathrm{H}) ; 7.48(\mathrm{~d}, J=$ 7.9, 2H); $6.83(\mathrm{~s}, 1 \mathrm{H}) ; 5.96(\mathrm{~d}, J=17.7,1 \mathrm{H}) ; 5.73(\mathrm{~s}, 2 \mathrm{H}) ; 5.48(\mathrm{~s}$, $2 \mathrm{H}) ; 5.39(\mathrm{~d}, J=11.0,1 \mathrm{H}) .{ }^{13} \mathrm{C}-\mathrm{NMR}\left(101 \mathrm{MHz}, \mathrm{DMSO}-d_{6}\right): 139.0$; $138.1 ; 137.4 ; 136.4 ; 134.5 ; 129.2 ; 127.1 ; 123.6 ; 123.3 ; 115.8 ; 52.3$. HR-ESI-MS: $365.1081\left(\mathrm{C}_{19} \mathrm{H}_{14} \mathrm{~F}_{5} \mathrm{~N}_{2}{ }^{+}, \mathrm{M}^{+}\right.$; calc. 365.1072$)$. Anal. calc. for $\mathrm{C}_{19} \mathrm{H}_{14} \mathrm{BrF}_{5} \mathrm{~N}_{2}$ (445.22): $\mathrm{C}$ 51.26, $\mathrm{H}$ 3.17, $\mathrm{N}$ 6.29; found: C 51.05, H 3.30, N 6.04.

\section{Synthesis of ATC}

Powdered pyrocatechol $(11.01 \mathrm{~g}, 100 \mathrm{mmol})$ was added to icecooled sulfuric acid $(220 \mathrm{~mL}, 70 \%)$ to give a colorless suspension. 2,5-Hexanedione $(5.71 \mathrm{~g}, 50 \mathrm{mmol})$ was added drop-wise to form a green mixture. After 1 hour of stirring, the ice bath was removed and the color of the mixture turned to reddish-brown and stirring was continued for $7 \mathrm{~d}$ at room temperature. The precipitate was removed from the acid by filtration with a glass frit and washed with water. The dark red crude product was recrystallized twice from ethyl acetate, then filtrated and dried under vacuum to form light gray powder. Yield: $71 \%$. Mp $265{ }^{\circ} \mathrm{C}$. FT-IR (neat): 3497, 3295, 2945, 1617, 1445, 1297, 1220, 1139, 992, 879, 813, $802 \mathrm{~cm}^{-1} .{ }^{1} \mathrm{H}$ NMR (400 MHz, DMSO- $\left.d_{6}\right)$ 
$\delta 8.41(\mathrm{~s}, 4 \mathrm{H}), 6.61(\mathrm{~s}, 4 \mathrm{H}), 1.68(\mathrm{~s}, 6 \mathrm{H}), 1.41(\mathrm{~s}, 4 \mathrm{H}) .{ }^{13} \mathrm{C}$ NMR $\left(101 \mathrm{MHz}, \mathrm{DMSO}-d_{6}\right) \delta 142.2,138.1,109.2,36.7,19.0$.

\section{Synthesis of PPZ nanospheres}

HCCP (300 mg, $0.862 \mathrm{mmol}$ ) and ATC (385 mg, $1.293 \mathrm{mmol}$ ) were mixed in acetonitrile $(120 \mathrm{~mL})$ and triethylamine (TEA) (522 $\mathrm{mg}, 5.17 \mathrm{mmol}$ ) was added. The reaction mixture was stirred in an ultrasonic bath $(100 \mathrm{~W}, 80 \mathrm{kHz})$ at room temperature for $5 \mathrm{~h}$. The resulting precipitate was collected by centrifugation at $6000 \mathrm{rpm}$ for $6 \mathrm{~min}$ and then washed three times with tetrahydrofuran and water. The collected solid was dried under vacuum to yield light brown powder (435 mg, yield 88\%, based on HCCP used).

\section{Synthesis of the PPZ-TBAB and PPZ-Bu2Im nanoreactors}

TBAB (33 mg, $2.5 \mathrm{~mol} \%$ ) or Bu2Im (24.3 mg, $1.25 \mathrm{~mol} \%$ ) was dissolved in acetone $(300 \mu \mathrm{L})$, and PPZ $(19.2 \mathrm{mg}$, containing $2.5 \mathrm{~mol} \% \mathrm{~N}$ ) was added and the solution heated at $40^{\circ} \mathrm{C}$ for $6 \mathrm{~h}$ under $\mathrm{N}_{2}$. The solvent was evaporated and dried under vacuum to afford the desired material.

\section{Computational details}

Gas phase calculations were carried out at the $\mathrm{M} 062 \mathrm{X}^{30} / 6-31 \mathrm{G}^{*}$ level using the Gaussian 09 suite of programs, ${ }^{31}$ and DGDZVP basis set was employed for iodide, ${ }^{32}$ as it has been used to describe iodide anions in related systems. ${ }^{33}$ M06-2X functional has demonstrated to be suitable for describing non-bonding interaction $^{34}$ including ionic hydrogen bonds. $^{35}$ The compounds were optimized and all structures were confirmed as minima by Hessian matrix calculations. Two constraints were included in order to avoid deformations of the PPZ cavity which are not representative of the system considering the effect of the surrounding polymer and the multiple layer nature of this material. Relevant vibrational frequencies were calculated at the same level of theory showing acceptable accuracy to describe the more relevant vibrational modes in the isolated ILs (see ESI $\dagger$ ). Whereas, binding energies were estimated at M062X/ 6-311G*//M062X/6-31G* level, as a difference between energy of a given adduct and the sum of energies of isolated components constituting it, and including zero-point vibrational energies. It is worth to mention that Coulomb interactions were not considered due to the size of the system and the required computational cost in order to avoid self-interaction errors. ${ }^{36}$

\section{Characterization in the solid-state}

${ }^{31} \mathrm{P}$ and ${ }^{13} \mathrm{C}$ NMR spectra were recorded on a Bruker AvanceIIIHD 400 spectrometer operating at $100.6 \mathrm{MHz}$ for ${ }^{13} \mathrm{C}$ and $162.0 \mathrm{MHz}$ for ${ }^{31} \mathrm{P}$. All experiments were performed at ambient probe temperature using hydrogen high-power decoupling. Crosspolarization with magic angle spinning (CP/MAS) was adopted. Liquid-state ${ }^{1} \mathrm{H}$ and ${ }^{13} \mathrm{C}$ NMR spectra were recorded on a Bruker $400 \mathrm{MHz}$ instrument. Fourier transform infrared (FT-IR) spectra were recorded on a Bruker Vertex 80 instrument. Mass spectra were recorded on a Bruker MALDI-TOF AutoFlex speed machine. Field emission SEM images were obtained using a Merlin instrument at an activation voltage of $2 \mathrm{kV}$ under high resolution analysis mode. TEM and STEM microphotographs were recorded on a Tecnai Osiris instrument at an activation voltage of $200 \mathrm{kV}$. The number-average diameter $\left(D_{\mathrm{n}}\right)$ and the standard deviation (SD) were determined with Image Tool software by counting 1000 individual particles from TEM microphotographs. BrunauerEmmett-Teller (BET) experiments were performed on a Quantachrome Autosorb-IQ/MP-XR with $\mathrm{N}_{2}(77 \mathrm{~K}), \mathrm{CO}_{2}(273 \mathrm{~K})$ and $\mathrm{CH}_{4}$ $(273 \mathrm{~K})$ as analyte gases. Atomic force microscopy (AFM) images were collected on a Cypher S AFM (Asylum Research) in tapping mode under ambient conditions. The dry PPZ sample was prepared by dropping an acetone suspension $\left(1 \mathrm{mg} \mathrm{mL}^{-1}\right)$ on a silicon wafer, then dried with $\mathrm{N}_{2}$ and kept under vacuum for $3 \mathrm{~d}$. The swelled PPZ sample was prepared by dropping the styrene oxide suspension ( $1 \mathrm{mg} \mathrm{mL}^{-1}$ ) on a silicon wafer, dried with $\mathrm{N}_{2}$ until there was no apparent solvent stain. Powder X-ray diffraction (PXRD) patterns were collected on a powder diffractometer (D/ max-2200/PC, Rigaku, Japan) using Cu-K irradiation (40 kV, 20 $\mathrm{mA}$ ). Diffraction patterns were collected from $8^{\circ}$ to $80^{\circ}$ at a speed of $5^{\circ} \mathrm{min}^{-1}$. Thermal degradation of the crosslinked microspheres was examined with a thermogravimetric analyzer (TGA) Perkin Elmer TGA-7 with a heating rate of $10{ }^{\circ} \mathrm{C} \mathrm{min}^{-1}$ under nitrogen condition. Dynamic light scattering (DLS) measurements were carried out on a Zeta sizer Nano ZS from Malvern Instruments with a laser at $633 \mathrm{~nm}$.

\section{Catalytic studies}

Typical procedure for reactions at an atmospheric pressure of $\mathrm{CO}_{2}$ : a mixture of styrene oxide $(480 \mathrm{mg}, 4 \mathrm{mmol})$ and the TBAB (33 mg, $2.5 \mathrm{~mol} \%$ ) with or without PPZ (19.2 mg, containing $2.5 \mathrm{~mol} \% \mathrm{~N}$ ) was heated at $57{ }^{\circ} \mathrm{C}$ for $20 \mathrm{~h}$ under a $\mathrm{CO}_{2}$ atmosphere ( $1 \mathrm{~atm}$, using a balloon). After the reaction, the system was cooled to room temperature and the products were analyzed by ${ }^{1} \mathrm{H}$ NMR spectroscopy. For the bis-imidazolium salts 1.25 mol\% were used.

Typical procedure for reactions under high $\mathrm{CO}_{2}$ pressures: to a $100 \mathrm{~mL}$ stainless steel autoclave equipped with a glass vial and a magnetic stirrer, propylene oxide (232 $\mathrm{mg}, 4 \mathrm{mmol}$ ), Bu2Im (23.7 mg, $1.25 \mathrm{~mol} \%$ ) and PPZ (19.2 mg, containing $2.5 \mathrm{~mol} \% \mathrm{~N}$ ) were added. The autoclave was sealed and purged three times with $\mathrm{CO}_{2}$ and then set to 10 bar. The autoclave was heated in a $57^{\circ} \mathrm{C}$ oil bath. After reaction, the autoclave was cooled in an ice bath and the yield of the product was determined by ${ }^{1} \mathrm{H}$ NMR spectroscopy.

\section{Kinetic study}

A mixture of styrene oxide (1920 mg, $16 \mathrm{mmol}$ ) and Bu2Im (94.8 mg, $1.25 \mathrm{~mol} \%$ ) with or without PPZ (76.8 mg, containing $2.5 \mathrm{~mol} \% \mathrm{~N})$ were heated at $57^{\circ} \mathrm{C}$ under a $\mathrm{CO}_{2}$ atmosphere $(1 \mathrm{~atm}$, using a balloon). After the appropriate time (1-20 h), one drop of the reaction mixture was removed and the sample was diluted with $\mathrm{CDCl}_{3}(0.5 \mathrm{~mL})$ and analyzed by ${ }^{1} \mathrm{H}$ NMR spectroscopy.

\section{Recycling experiments}

The experiments were conducted according to the typical procedure at atmospheric pressure. In addition, the PPZ-Bu2Im catalyst was further washed with ethyl acetate and dried before reuse. 


\section{Conflicts of interest}

There are no conflicts to declare.

\section{Acknowledgements}

This work is supported by the Sino Swiss Science and Technology Cooperation (SSSTC) Program. We are grateful to Dr Kurt Schenk for helpful discussions, Baudat Emilie for recording the solid-state NMR spectra, Xavier Adrian Jeanbourquin Vasilyev for AFM, and José Bila for BET.

\section{References}

1 (a) A. P. Cote, A. I. Benin, N. W. Ockwig, M. O'keeffe, A. J. Matzger and O. M. Yaghi, Science, 2005, 310, 11661170; (b) X. Feng, X. Ding and D. Jiang, Chem. Soc. Rev., 2012, 41, 6010-6022.

2 (a) D. Yuan, W. Lu, D. Zhao and H. C. Zhou, Adv. Mater., 2011, 23, 3723-3725; (b) C. J. Doonan, D. J. Tranchemontagne, T. G. Glover, J. R. Hunt and O. M. Yaghi, Nat. Chem., 2010, 2, 235-238.

3 (a) H. Oh, S. B. Kalidindi, Y. Um, S. Bureekaew, R. Schmid, R. A. Fischer and M. Hirscher, Angew. Chem., Int. Ed., 2013, 52, 13219-13222; (b) S. Keskin, J. Phys. Chem. C, 2012, 116, 1772-1779; (c) H. Ma, H. Ren, S. Meng, Z. Yan, H. Zhao, F. Sun and G. Zhu, Chem. Commun., 2013, 49, 9773-9775.

4 (a) S. Dalapati, E. Jin, M. Addicoat, T. Heine and D. Jiang, J. Am. Chem. Soc., 2016, 138, 5797-5800; (b) S. Y. Ding, M. Dong, Y. W. Wang, Y. T. Chen, H. Z. Wang, C. Y. Su and W. Wang, J. Am. Chem. Soc., 2016, 138, 3031-3037; (c) G. Lin, H. Ding, D. Yuan, B. Wang and C. Wang, J. Am. Chem. Soc., 2016, 138, 3302-3305.

5 (a) G. H. Bertrand, V. K. Michaelis, T. C. Ong, R. G. Griffin and M. Dincă, Proc. Natl. Acad. Sci. U. S. A., 2013, 110, 4923-4928; (b) D. D. Medina, M. L. Petrus, A. N. Jumabekov, J. T. Margraf, S. Weinberger, J. M. Rotter, T. Clark and T. Bein, ACS Nano, 2017, 11, 2706-2713; (c) M. Calik, F. Auras, L. M. Salonen, K. Bader, I. Grill, M. Handloser, D. D. Medina, M. Dogru, F. Löbermann and D. Trauner, J. Am. Chem. Soc., 2014, 136, 17802-17807; (d) L. Chen, K. Furukawa, J. Gao, A. Nagai, T. Nakamura, Y. Dong and D. Jiang, J. Am. Chem. Soc., 2014, 136, 98069809.

6 (a) A. Larrañaga, M. Lomora, J. Sarasua, C. Palivan and A. Pandit, Prog. Mater. Sci., 2017, 90, 325-357; (b) Q. Fang, J. Wang, S. Gu, R. B. Kaspar, Z. Zhuang, J. Zheng, H. Guo, S. Qiu and Y. Yan, J. Am. Chem. Soc., 2015, 137, 8352-8355; (c) V. S. Vyas, M. Vishwakarma, I. Moudrakovski, F. Haase, G. Savasci, C. Ochsenfeld, J. P. Spatz and B. V. Lotsch, Adv. Mater., 2016, 28, 8749-8754.

7 (a) F. Wu, E. Zhao, D. Gordon, Y. Xiao, C. Hu and G. Yushin, Adv. Mater., 2016, 28, 6365-6371; (b) C. R. DeBlase, K. H. Burgos, K. E. Silberstein, G. G. R. Calero, R. P. Bisbey, H. D. Abruna and W. R. Dichtel, ACS Nano, 2015, 9, 31783183; (c) C. R. DeBlase, K. E. Silberstein, T. T. Truong, H. D. Abruña and W. R. Dichtel, J. Am. Chem. Soc., 2013, 135,
16821-16824; (d) H. Liao, H. Wang, H. Ding, X. Meng, H. Xu, B. Wang, X. Ai and C. Wang, J. Mater. Chem. A, 2016, 4, 7416-7421; (e) C. R. Mulzer, L. Shen, R. P. Bisbey, J. R. McKone, N. Zhang, H. D. Abruña and W. R. Dichtel, ACS Cent. Sci., 2016, 2, 667-673; (f) F. Xu, H. Xu, X. Chen, D. $\mathrm{Wu}, \mathrm{Y} . \mathrm{Wu}, \mathrm{H} . \mathrm{Liu}, \mathrm{C} . \mathrm{Gu}, \mathrm{R} . \mathrm{Fu}$ and D. Jiang, Angew. Chem., Int. Ed., 2015, 54, 6814-6818.

8 (a) H. B. Aiyappa, J. Thote, D. B. Shinde, R. Banerjee and S. Kurungot, Chem. Mater., 2016, 28, 4375-4379; (b) S. Y. Ding, J. Gao, Q. Wang, Y. Zhang, W. G. Song, C. Y. Su and W. Wang, J. Am. Chem. Soc., 2011, 133, 19816-19822; (c) Q. Fang, S. Gu, J. Zheng, Z. Zhuang, S. Qiu and Y. Yan, Angew. Chem., Int. Ed., 2014, 53, 2878-2882; (d) S. Lin, C. S. Diercks, Y. B. Zhang, N. Kornienko, E. M. Nichols, Y. Zhao, A. R. Paris, D. Kim, P. Yang and O. M. Yaghi, Science, 2015, 349, 1208-1213; (e) H. Xu, J. Gao and D. Jiang, Nat. Chem., 2015, 7, 905-912; (f) X. Wang, X. Han, J. Zhang, X. Wu, Y. Liu and Y. Cui, J. Am. Chem. Soc., 2016, 138, 12332-12335.

9 D. N. Bunck and W. R. Dichtel, J. Am. Chem. Soc., 2013, 135, 14952-14955.

10 O. R. Evans, H. L. Ngo and W. Lin, J. Am. Chem. Soc., 2001, 123, 10395-10396.

11 M. L. Foo, R. Matsuda, Y. Hijikata, R. Krishna, H. Sato, S. Horike, A. Hori, J. Duan, Y. Sato and Y. Kubota, J. Am. Chem. Soc., 2016, 138, 3022-3030.

12 Q. Sun, B. Aguila, J. Perman, N. Nguyen and S. Ma, J. Am. Chem. Soc., 2016, 138, 15790-15796.

13 (a) W. Zhong, F. D. Bobbink, Z. Fei and P. J. Dyson, ChemSusChem, 2017, 10, 2728-2735; (b) F. D. Bobbink, A. P. Van Muyden, A. Gopakumar, Z. Fei and P. J. Dyson, ChemPlusChem, 2017, 82, 144-151.

14 (a) P. Mohanty, L. D. Kull and K. Landskron, Nat. Commun., 2011, 2, 401; (b) H. R. Allcock, Accounts Chem. Res., 1978, 11, $81-87$.

15 (a) W. Y. Gao, Y. Chen, Y. Niu, K. Williams, L. Cash, P. J. Perez, L. Wojtas, J. Cai, Y. S. Chen and S. Ma, Angew. Chem., Int. Ed., 2014, 53, 2615-2619; (b) J. Dong, P. Cui, P. F. Shi, P. Cheng and B. Zhao, J. Am. Chem. Soc., 2015, 137, 15988-15991; (c) M. H. Beyzavi, R. C. Klet, S. Tussupbayev, J. Borycz, N. A. Vermeulen, C. J. Cramer, J. F. Stoddart, J. T. Hupp and O. K. Farha, J. Am. Chem. Soc., 2014, 136, 15861-15864; (d) P. Z. Li, X. J. Wang, J. Liu, J. S. Lim, R. Zou and Y. Zhao, J. Am. Chem. Soc., 2016, 138, 2142-2145; (e) Z. Zhou, C. He, J. Xiu, L. Yang and C. Duan, J. Am. Chem. Soc., 2015, 137, 15066-15069; (f) S. Kaneko and S. Shirakawa, ACS Sustainable Chem. Eng., 2017, 5, 2836-2840.

16 (a) L. Zhu, Y. Xu, W. Yuan, J. Xi, X. Huang, X. Tang and S. Zheng, Adv. Mater., 2006, 18, 2997-3000; (b) J. Zhou, L. Meng, X. Feng, X. Zhang and Q. Lu, Angew. Chem., Int. Ed., 2010, 49, 8476-8479.

17 (a) H. Liu, S. Li, H. Yang, S. Liu, L. Chen, Z. Tang, R. Fu and D. Wu, Adv. Mater., 2017, 29, 1700723; (b) J. X. Jiang, F. Su, A. Trewin, C. D. Wood, N. L. Campbell, H. Niu, C. Dickinson, A. Y. Ganin, M. J. Rosseinsky and Y. Z. Khimyak, Angew. Chem., Int. Ed., 2007, 46, 8574-8578. 
18 M. J. Bojdys, J. Jeromenok, A. Thomas and M. Antonietti, Adv. Mater., 2010, 22, 2202-2205.

19 (a) L. Du, Z. Lu, K. Zheng, J. Wang, X. Zheng, Y. Pan, X. You and J. Bai, J. Am. Chem. Soc., 2012, 135, 562-565; (b) S. Yang, X. Lin, W. Lewis, M. Suyetin, E. Bichoutskaia, J. E. Parker, C. C. Tang, D. R. Allan, P. J. Rizkallah and P. Hubberstey, Nat. Mater., 2012, 11, 710-716.

20 (a) Q. Liu, L. Wu, R. Jackstell and M. Beller, Nat. Commun., 2015, 6, 5933; (b) F. D. Bobbink and P. J. Dyson, J. Catal., 2016, 343, 52-61.

21 J. H. Clements, Ind. Eng. Chem. Res., 2003, 42, 663-674.

22 H. Sun and D. Zhang, J. Phys. Chem. A, 2007, 111, 8036-8043.

23 J. Liang, Y. B. Huang and R. Cao, Coord. Chem. Rev., 2017, DOI: 10.1016/j.ccr.2017.11.013.

24 A. Mirabaud, J. C. Mulatier, A. Martinez, J. P. Dutasta and V. R. Dufaud, ACS Catal., 2015, 5, 6748-6752.

25 (a) D.-H. Lan, Y.-X. Gong, N.-Y. Tan, S.-S. Wu, J. Shen, K.-C. Yao, B. Yi, C.-T. Au and S.-F. Yin, Carbon, 2018, 127, 245-254; (b) D.-H. Lan, H.-T. Wang, L. Chen, C.-T. Au and S.-F. Yin, Carbon, 2016, 100, 81-89; (c) D.-H. Lan, L. Chen, C.-T. $\mathrm{Au}$ and S.-F. Yin, Carbon, 2015, 93, 22-31; (d) D. H. Lan, N. Fan, Y. Wang, X. Gao, P. Zhang, L. Chen, C. T. Au and S. F. Yin, Chin. J. Catal., 2016, 37, 826-845; (e) D. H. Lan, F. M. Yang, S. L. Luo, C. T. Au and S. F. Yin, Carbon, 2014, 73, 351-360.

26 (a) S. A. Katsyuba, M. V. Vener, E. E. Zvereva, Z. Fei, R. Scopelliti, G. Laurenczy, N. Yan, E. Paunescu and P. J. Dyson, J. Phys. Chem. B, 2013, 117, 9094-9105; (b) S. A. Katsyuba, M. V. Vener, E. E. Zvereva, Z. Fei, R. Scopelliti, G. Laurenczy, J. G. Brandenburg, S. Siankevich and P. J. Dyson, J. Phys. Chem. Lett., 2015, 6, 4431-4436.

27 E. Arunan, G. R. Desiraju, R. A. Klein, J. Sadlej, S. Scheiner, I. Alkorta, D. C. Clary, R. H. Crabtree, J. J. Dannenberg,
P. Hobza, et al., Definition of the Hydrogen Bond (IUPAC Recommendations 2011), Pure Appl. Chem., 2011, 83, 16371641.

28 D. E. Newbury and N. W. Ritchie, J. Anal. At. Spectrom., 2013, 28, 973-988.

29 (a) D. Peixoto, M. Figueiredo, M. B. Gawande, M. C. Corvo, G. Vanhoenacker, C. A. Afonso, L. M. Ferreira and P. S. Branco, J. Org. Chem., 2017, 82, 6223-6231; (b) T. V. Goncharova, L. V. Zatonskaya and A. S. Potapov, Procedia Chem., 2014, 10, 485-489; (c) J. Arcau, V. Andermark, M. Rodrigues, I. Giannicchi, L. Pérez Garcia, I. Ott and L. Rodríguez, Eur. J. Inorg. Chem., 2014, 2014, 6117-6125; (d) S. Li, J. Tang, Y. Zhao, R. Jiang, T. Wang, G. Gao and J. You, Chem. Commun., 2017, 53, 3489-3492; (e) F. D. Bobbink, Z. Fei, R. Scopelliti, S. Das and P. J. Dyson, Helv. Chim. Acta, 2016, 99, 821-829; (f) D. Fritsch, G. Bengtson, M. Carta and N. B. McKeown, Macromol. Chem. Phys., 2011, 212, 1137-1146.

30 Y. Zhao and D. G. Truhlar, Theor. Chem. Acc., 2008, 120, 215241.

31 M. J. Frisch, et al., Gaussian 09, Revision D.01, Gaussian, Inc., Wallingford, CT, USA, 2009.

32 N. Godbout, D. R. Salahub, J. Andzelm and E. Wimmer, Can. J. Chem., 1992, 70, 560-571.

33 M. Aono, H. Miyazaki, T. Takekiyo, S. Tsuzuki and H. Abe, Phys. Chem. Chem. Phys., 2018, 20, 5780-5784.

34 N. Mardirossian and M. Head-Gordon, J. Chem. Theory Comput., 2016, 12, 4303-4325.

35 M. Walker, A. J. A. Harvey, A. Sen and Ca. E. H. Dessent, J. Phys. Chem. A, 2013, 117, 12590-12600.

36 (a) M. V. Fedorov and A. A. Kornyshev, Chem. Rev., 2014, 114, 2978-3036; (b) I. Lage-Estebanez, A. Ruzanov, J. M. García de la Vega, M. V. Fedorov and V. B. Ivaništšev, Phys. Chem. Chem. Phys., 2016, 18, 2175-2182. 